\title{
A procedure to assess suitability of plaster to protect vernacular earthen architecture
}

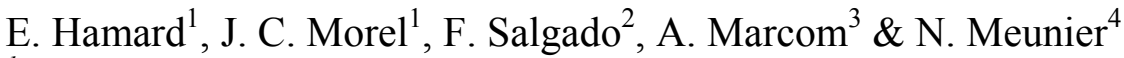 \\ ${ }^{1}$ Ecole Nationale des Travaux Publics de l'Etat-ENTPE, France \\ ${ }^{2}$ Pontifícia Universidade Católica do Rio de Janeiro - PUC-Rio, Brasil \\ ${ }^{3}$ Inventerre, Saint Pierre de Lages, France \\ ${ }^{4} N$. Meunier, 6 rue de l'Eglise, 42170 Chambles, France
}

\begin{abstract}
As part of a working definition of a new code of practice, a methodology is being defined to determine the suitability of plasters manufactured on-site to protect earthen wall of vernacular architecture buildings. Given the diversity of raw earth construction methods, ranging from massive earth to stone masonry with earth mortars, and the variability of the materials used, it was proposed two on-site testing: a shrinkage test followed by a shear test. These tests, as well as additional tests, were performed on an earthen wall using two different earth plasters. This first testing campaign has permitted to validate the on-site shrinkage test but not the on-site shear test. A future testing campaign will explore the influence of various parameters on the shear test.

Keywords: earth plaster, earthen vernacular architecture, durability, on-site coating testing.
\end{abstract}

\section{Introduction}

Historic earthen buildings represent an important, though difficult to quantify, part of the human habitat worldwide. In France, according to Michel and Poudru [1], in 1987 there were approximately one million earth houses (rammed earth, adobe and cob) with average ages of 100 years. All of them have more than 50 years old. This heritage ought to be preserved. One of the major issues is the repair of their protective plasters. Unfortunately, old construction techniques fell into disuse in the West and are therefore no longer controlled by the vast majority of today masons. Industrial ready-to-use coatings are unsuitable and even harmful to earth constructions [2,3]. As part of a working definition of a new code of practice for plaster implementing on earthen walls, we conducted a 
research campaign to validate on-site tests to select suitable plaster formulations. This study focuses on the earth plasters mechanical behaviour.

Earth plasters feature two advantages: they are permeable to water vapour and their mechanical behaviour is close to earthen walls, which make them more compatible than industrial coatings that are waterproof and too stiff $[2,3]$. Indeed, the mechanical compatibility can be estimated taking into account the difference between the Young's modulus of the wall and the plaster. If this difference is too high, the stress changes induced by overloads, by moisture and by temperature variations, generate a differential strains between the plaster and the wall. Those two elements are linked, leading to damages in the plaster or in the earthen wall. Earthen wall Young Modulus (ranging from 0.5 to $1 \mathrm{GPa}$ for rammed earth $[4,5]$ ) are much lower than concrete modulus (ranging from 15 to $50 \mathrm{GPa}$ ). That is why earth plasters (close to earth mortar and adobe with a Young modulus ranging from 0.5 to $2.5 \mathrm{GPa}$ [6]) and lime/sand plasters [7] are a priori well adapted to earthen walls.

Earth plasters are made from clayey soils called earths, extracted near the construction site, to which is added a certain amount of sand. Numerous admixtures can be added to these two bases, as masons used to do for centuries, to improve their behaviour, for example: vegetable and animal fibres, soap, milk, fresh cow dung, red wine [8-11]. Unlike standardized building materials, materials entering in the composition of earth plasters have a considerable variability. It is not possible to propose a calculation of formulating adapted to all sites. This is why, inspired by tests already carried out by the masons, field tests are proposed to validate plasters formulations, whatever is the nature of materials used. This approach is designed to allow the choice of materials at the discretion of the mason, thus promoting the use of local materials and respecting local constructive cultures.

An earth plaster of acceptable mechanical quality is a plaster which, after shrinkage, has no cracks that could allow water penetration into the wall and has a sufficient bond with its wall. It is proposed here two on-site tests to validate the plaster formulations: a shrinkage test and a shear test. A first testing campaign was conducted to validate these two tests. The proposed tests were applied to plasters made from two different earths. Additional laboratory tests were conducted to measure the shrinkage, the tensile strength as well as the water content of these plasters.

\section{Experimental program}

\subsection{Earthen wall preparation}

For testing, it was used an earthen wall allocated in a farm garden belonging to the Grand Parc de Miribel Jonage (Lyon, France). This wall is composed of a base of slag concrete that underpins an earth rising of about $500 \mathrm{~mm}$. Before testing, the wall was brushed and repeatedly wetted with a garden sprayer. A scratch coat consisting of 1 volume of NHL 3.5 hydraulic lime and two volumes 
of Hostun sand [12] was thrown on the earthen wall. Earth plasters are performed directly on this scratch coat.

\subsection{Testing campaign}

Earth plasters were prepared from earth (clays, silts and sand) added with variable proportion of sand and water. Clays play the role of binder and are responsible for the shrinkage of the plaster. Silts and sands form the granular skeleton that gives the mechanical structure of the plaster. Most of the time, there is not enough sand in the natural earth and this is why it had to be added.

A good earth plaster formulation must contain enough clay to bind the entire granular skeleton and avoid its erosion, but not too much to limit its shrinkage. Therefore it is usual to seek the ration earth:sand by volume or by mass which will generate no harmful shrinkage to plaster and will allow a sufficient sand grains covering. In this study, shrinkage is considered harmful if it causes deep cracks or a bow out of the plaster; cracking is not considered injurious.

The shrinkage test requires a sample for each formulation created in two layers of brown coat of $250 \mathrm{~mm}$ by $250 \mathrm{~mm}$ and $20 \mathrm{~mm}$ thick. After drying, when shrinkage is completed, the presence or absence of shrinkage cracks in the samples was noted. Only samples with no shrinkage cracks were validated.

A second important point to validate earth plaster formulations is their bond on the wall. This bond depends on the nature of the wall (sources of materials, material implementation and possible heterogeneities), on the wall hydric state and on the nature of the plaster. Since the tests were performed in the closest possible on-site conditions and on different parts of the wall, these parameters need not be considered.

Two samples for each formulation of $50 \mathrm{~mm} \times 40 \mathrm{~mm}$ and $20 \mathrm{~mm}$ thick were shaped in a single layer for the shear test. It was also used the $250 \mathrm{~mm} \times 250 \mathrm{~mm}$

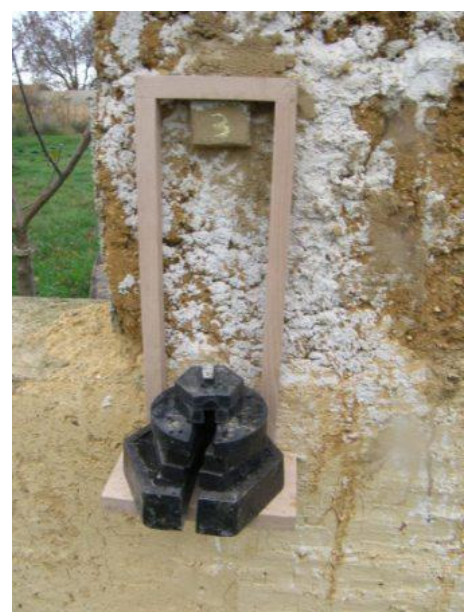

Figure 1: $\quad$ Load device. 
samples in the shrinkage test. They were cut in order to get 4 samples of $50 \mathrm{~mm}$ $\times 40 \mathrm{~mm}$ and $20 \mathrm{~mm}$ thick. Thus, 6 samples were obtained per formulation: 2 "shaped" and 4 "cut". Samples were loaded up to failure with a load device (fig. 1), by increment of $0.5 \mathrm{~kg}$ every $60 \mathrm{~s}$ for T17.5, T12, T9 and T6 samples (table 1 and 2) and then, for reasons of precision, loaded by increment of $0.25 \mathrm{~kg}$ every $30 \mathrm{~s}$ for the other samples.

Knowing loads and the surface of the sample $\left(\mathrm{S}, \mathrm{mm}^{2}\right)$ it is possible to calculate the shear rate $\left(\tau, \mathrm{N} . \mathrm{mm}^{-2}\right)$ :

$$
\tau=\frac{\mathrm{m}_{\mathrm{f}} \cdot \mathrm{g}}{\mathrm{S}}
$$

with $\mathrm{g}=9.81 \mathrm{~m} . \mathrm{s}^{-2}$

Additional laboratory tests were carried out to better characterize the earth plaster:

- Measurement of the plaster's longitudinal shrinkage for samples of $40 \mathrm{~mm} \times 40$ $\mathrm{mm} \times 160 \mathrm{~mm}$;

- Three points bending test on plaster samples of $40 \mathrm{~mm} \times 40 \mathrm{~mm} \times 160 \mathrm{~mm}$.

The maximal force reached $(\mathrm{F}, \mathrm{N})$ was recorded and the bending strength $(\sigma$, N.mm ${ }^{-2}$ ) was calculated:

$$
\sigma= \pm \frac{1,5 \cdot \mathrm{F} \cdot \mathrm{d}}{\mathrm{w} \cdot \mathrm{h}^{2}}
$$

where:

$-\mathrm{d}(\mathrm{mm})$ is the distance between lower supports points

- $\mathrm{W}(\mathrm{mm})$ is the width of the specimen

- $\mathrm{h}(\mathrm{mm})$ is the height of the samples

The bending strength is equal to the tensile strength, since tensile failure occurs before compression in this pure bending test.

\subsection{Sample production}

Two earths were used in the tests: Tassin and Rochechinard earths [6] (table 1). Four different clay contents were aimed: $17.5 \%, 12 \%, 9 \%$ and $6 \%$ in dry weight by adding Hostun sand [12]. The Rochechinard earth plasters with 17,5\% and $12 \%$ were also tested with $0.5 \%$ admixture by dry weight, Sisal fibres [13] and hemp chaff aggregate [14] (table 2). Finally a lime-sand plaster, composed of 1 volume of lime $(0.5 \%$ calcic lime and $0.5 \%$ natural hydraulic lime NHL 3.5$)$ and 3 volumes of Hostun sand, was also tested.

\begin{tabular}{|c|c|c|c|c|}
\hline & Clays $<2 \mu \mathrm{m}$ & $\begin{array}{c}2 \mu \mathrm{m}<\text { silts }<20 \\
\mu \mathrm{m}\end{array}$ & $\begin{array}{c}20 \mu \mathrm{m}<\text { sands }< \\
2000 \mu \mathrm{m}\end{array}$ & $\overline{M B V}$ \\
\hline Tassin & $17.5 \%$ & $12.5 \%$ & $70 \%$ & 1.4 \\
\hline Rochechinard & $25.5 \%$ & $32.5 \%$ & $42 \%$ & 2.5 \\
\hline
\end{tabular}

Table 1: $\quad$ Earths composition $(\mathrm{MBV}=$ Methylen Blue Value). 
Table 2: $\quad$ Earth plasters formulations.

\begin{tabular}{|c|c|c|c|c|c|c|c|c|c|c|c|c|}
\hline \multirow{2}{*}{\begin{tabular}{|c} 
Earth \\
$\begin{array}{c}\text { Sample } \\
\text { name }\end{array}$
\end{tabular}} & \multicolumn{4}{|c|}{ Tassin } & \multicolumn{4}{|c|}{ Rochechinard } & \multicolumn{4}{|c|}{ Rochechinard with admixtures } \\
\hline & T17.5 & T12 & T9 & T6 & R17.5 & R12 & R9 & R6 & $\begin{array}{l}\text { R17.5 } \\
+\mathrm{S}\end{array}$ & $\begin{array}{l}\mathrm{R} 12 \\
+\mathrm{S}\end{array}$ & $\begin{array}{l}\text { R17.5 } \\
+\mathrm{H}\end{array}$ & $\begin{array}{l}\mathrm{R} 12 \\
+\mathrm{H}\end{array}$ \\
\hline Clay (\%) & 17.5 & 12 & 9 & 6 & 17.5 & 12 & 9 & 6 & 17.5 & 12 & 17.5 & 12 \\
\hline Earth (kg) & 5 & 3.43 & 2.57 & 1.71 & 3.43 & 2.35 & 1.76 & 1.18 & 3.43 & 2.35 & 3.43 & 2.35 \\
\hline Sand (kg) & 0 & 1.57 & 2.43 & 3.29 & 1.57 & 2.65 & 3.24 & 3.82 & 1.57 & 2.65 & 1.57 & 2.65 \\
\hline $\begin{array}{c}\text { Hemp } \\
\text { chaff }(g)\end{array}$ & - & - & - & - & - & - & - & - & - & - & 25 & 25 \\
\hline Sisal (g) & - & - & - & - & - & - & - & - & 25 & 25 & - & - \\
\hline
\end{tabular}

Before the test, earth and sand are placed in an oven to dry. Then earth-sand mixtures were fabricated in the right proportions in the laboratory and bagged to keep them dry. On-site, the water amount considered necessary to obtain a good workability of the mortar was added. This amount of water was measured, which allowed to calculate their water content.

\section{Results and discussion}

\subsection{Shrinkage tests}

The results of the $250 \mathrm{~mm}$ by $250 \mathrm{~mm}$ squares shrinkage test are presented in figure 2. Tassin and Rochechinard $17.5 \%$ clay plasters fell from the wall; those with $12 \%$ clay cracked and $9 \%$ and $6 \%$ clay did not cracked. It was noted that the plasters with $6 \%$ clay were very sandy, which make them more difficult to work and relatively powdery after drying. Optimal clay content in this case is around 9\%. Clay content has a clear influence on earth plaster cracking. Tassin and Rochechinard earths presented a similar workability and shrinkage for the same clay content. This observation is consistent with the Methylen Blue Value of those earths which are of the same order (table 1).

The addition of Sisal fibres in the Rochechinard earth with $17.5 \%$ and $12 \%$ clay allows us to greatly improve the workability of the mortar. It is the same for cracking, since the $17.5 \%$ clay plaster without fibre, which fall from the wall, shows no cracks when $25 \mathrm{~g}$ of Sisal were added, even if it tends to bowed out. The $12 \%$ clay plaster with Sisal fibres would be validated unlike its counterpart without fibres.

Rochechinard earth plus $25 \mathrm{~g}$ hemp chaff aggregate has a workability identical to the one without fibres. The addition of $25 \mathrm{~g}$ of hemps chaff does not therefore improve the workability of the mortar. The shrinkage causes a bow out and some cracks on these earth plasters (R17.5 $+\mathrm{H}$ and R12 $+\mathrm{H}$ ). Even if cracking is less important for plasters with hemp chaff than for those with earth, none of those plasters could be validated. 


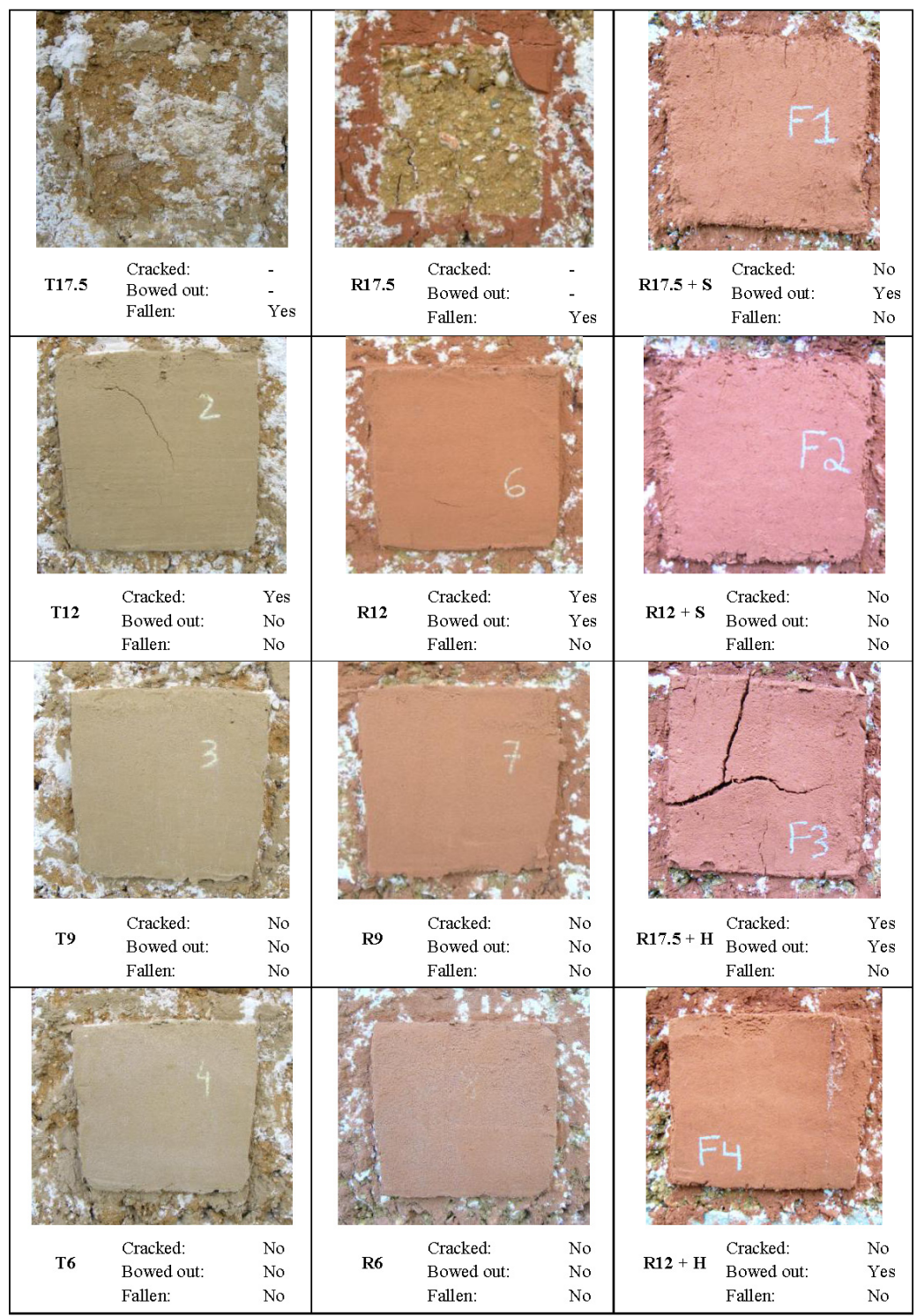

Figure 2: $\quad$ Results of the shrinkage test.

\subsection{Shear tests}

It was not possible to shape or cut the samples at the exact sizes, this is why the actual dimensions were measured and calculations were made with the real values. Some samples of $250 \times 250 \mathrm{~mm}$ could not be cut for the shear test, either because they fell before the test (T17.5 and R17.5), or because they were too bowed out and too cracked to be tested $(\mathrm{R} 17.5+\mathrm{H})$. Some samples badly 
supported cutting and could not be tested (one of the R17.5 $+\mathrm{S}$, and two of the $\mathrm{R} 12+\mathrm{H}$ samples, as well as all the lime-sand samples).

Shear test results showed (fig. 3):

- A greater strength of shaped samples compared to cut samples, which were cut with an angle grinder that damaged earth plaster and support by vibration. Shear strength values are weaker and more heterogeneous for cut samples than for shaped ones. Therefore cutting of samples should be banned,

- An optimum shear strength for a content of clay ranging between $6 \%$ and $8 \%$,

- A greater strength of lime-sand plasters samples in comparison to those made from earth,

- A large dispersion of the results that can be attributed to the heterogeneity of the wall.

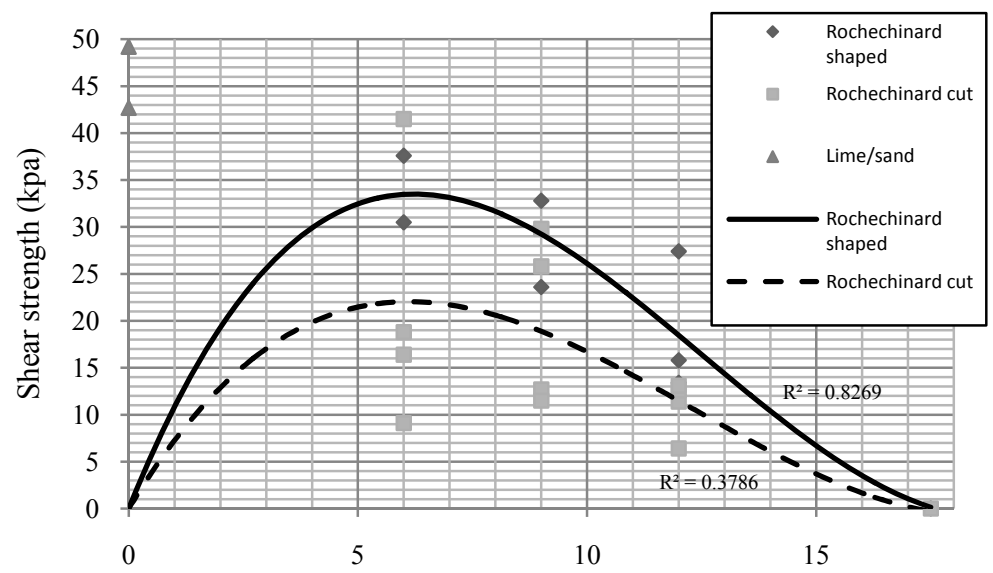

Clay content $(\%)$

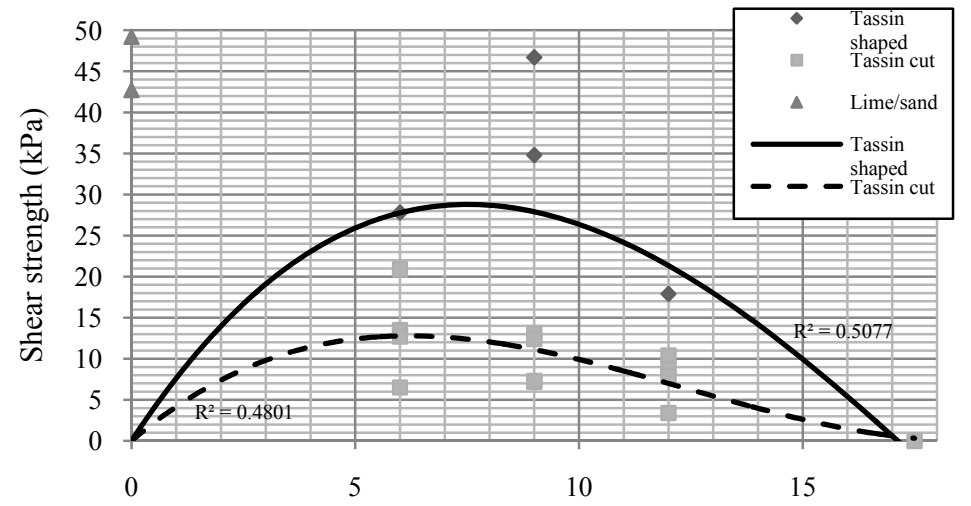

Clay content $(\%)$

Figure 3: Influence of clay content on shear strength for Rochechinard and Tassin earths. 


\subsection{Bending strength}

Three points bending strength tests results (fig. 4) revealed that:

- The bending strength increase with the increase of clay content,

- The lowest bending strength of the campaign was that of the lime-sand plasters.

This can be explained by the use of the very fine Hostun sand (maximum diameter of $0.8 \mathrm{~mm}$ ) that did not structured enough the plaster. It has probably happened also because the time lapse between manufacture and test (1 month) was not sufficient to enable a good setting of the calcic lime.

If increasing clay content in the earth plaster improves its bending strength (fig. 4), the shrinkage, which goes with clay content increase, limits and then cancels this effect (fig. 2). This can explain the existence of an optimum shear strength of earth plasters (fig. 3).

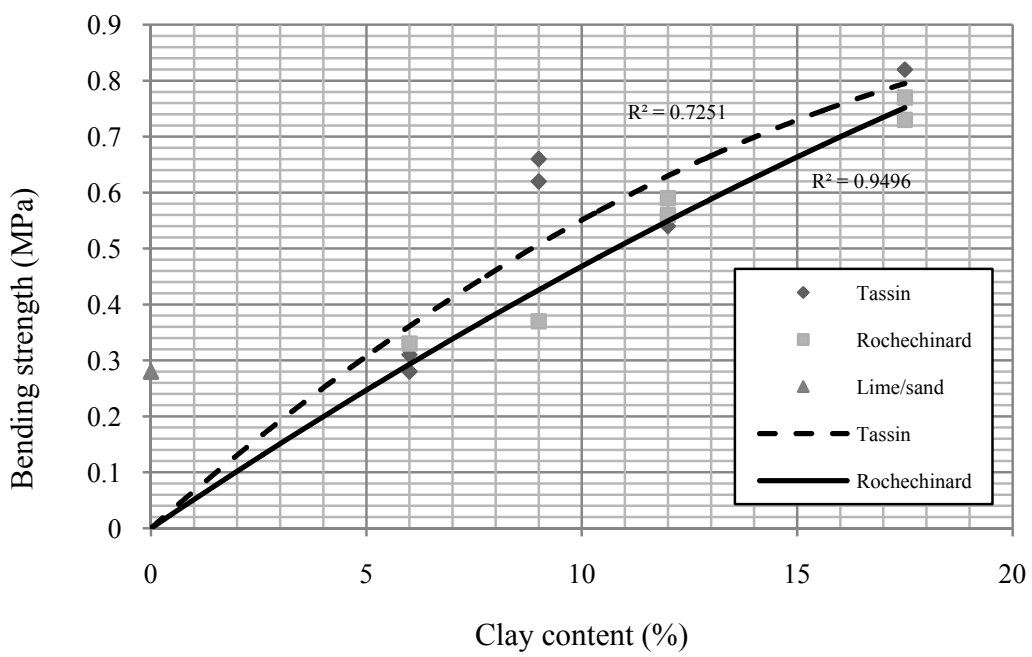

Figure 4: Influence of clay content on three point bending strength of earth plasters.

\section{Conclusion}

A significant current problem is the preservation of earthen vernacular buildings, which bear testimony of local constructive cultures and values of sustainable development. Non industrial materials used with raw earth require a suitable scientific approach.

The first test campaign has been very satisfactory for the on-site shrinkage test. Its experimental protocol can be validated. For the on-site shear test, cut samples were weakened and they cannot be considered in the experimental campaign. A future testing campaign will explore more systematically the on-site shear tests. This might allow us to better understand the influence of the different 
parameters that control shear resistance of the plaster on the wall and to propose well adapted on-site tests to assess the suitability of plasters to protect vernacular earthen architecture.

\section{Acknowledgements}

The authors wish to gratefully acknowledge Prof. Ghavami for having helped Fernanda Salgado do her Master course in France, the whole team who worked to realise the code of practice for their contribution and the Grand Parc de Miribel Jonage for providing us the Allivoz farm fence wall to allow us to achieve our tests.

\section{References}

[1] Michel P. and Poudru F., Le patrimoine construit en terre en France, actes du colloque international sur le patrimoine européen construit en terre et sa réhabilitation, ENTPE, (1987) 529-549.

[2] Lanas J., Alavarez J.L., Masonry repair lime based mortars: factors affecting the mechanical behavior, Cement and Concrete research 33 (2003) 1867-1876.

[3] Walker P., Keable R., Martin J., Maniatidis V., Rammed earth - design and construction guidelines, BRE Bookshop, 2005.

[4] Bui B., Morel J. C., Hans S., Meunier N., Compression behaviour of nonindustrial materials in civil engineering by three scale experiments: the case of rammed earth, Material and Structures 42 (2009) 1101-1116.

[5] Minke G., Earth construction handbook, the building materials earth in modern architecture, WIT Press, Southampton, UK, 2009.

[6] Alves de Azeredo G., Mise au point de procédures d'essais mécaniques sur mortier de terre: application à l'étude de leur rhéologie, PH.D. thesis, INSA Lyon, France, 2005.

[7] Arandigoyen M., Alvarez J. L., Pore structure and mechanical properties of cement-lime mortars, Cement and concrete research 37 (5) (2007) 767-775.

[8] Yetgin S., Cavdar Ö., Cavdar A., The effect of the fiber content on the mechanic properties of the adobes, Construction and Building Materials 22 (2008) 22-227.

[9] Achenza M., Fenu L., On earth stabilization with natural polymers for earth masonry construction, Material and Structures 39 (2006), 21-27.

[10] Quagliarini E., Lenci S., The influence of natural stabilizers and natural fibres on the mechanical properties of ancient Roman adobe bricks, Journal of Cultural Heritage 11 (3) (2010) 309-314.

[11] Galán-Marín C., Rivera-Gómez C., Petric J., Clay-based composite stabilized with natural polymer and fibre, Construction and Building Materials 24 (2010) 1462-1468.

[12] Flavigny E., Desrues J., Palayer B., Note technique - le sable d'hostun in Revue Française Géotechnique 53 (1990) 67-70. 
516 Structural Repairs and Maintenance of Heritage Architecture XII

[13] Ghavami K., Toledo Filho R.D., Barbosa N.P., Behaviour of composite soil reinforced with natural fibres, Cement and concrete composites 21 (1) (1999) 39-48.

[14] Samri D., Analyse physique et caractérisation hygrothermique des matériaux de construction: approche expérimentale et modélisation numérique, Ph.D. thesis, INSA Lyon, France, 2008. 